\title{
Fracture Toughness of Medium Molecular Weight Phenol Formaldehyde (MMwPF) Plywood
}

\author{
Hasmawi Khalid ${ }^{1,}$, Ahmad Muzaffar Abdul Aziz ${ }^{2}$ \\ Politeknik Sultan Salahuddin Abdul Aziz Shah, Persiaran Usahawan, Seksyen U1, 40150 Shah Alam, Selangor, Malaysia \\ Kolej Komuniti Bentong, KM 6, Karak Setia, 28600 Karak, Pahang, Malaysia
}

\section{ABSTRACT}

Currently in Malaysia, most of the plywood industries are using tropical hardwood veneer with combination of rubberwood to form plywood. The used of rubberwood has actively reduced the cost of plywood production but recently the price of rubberwood logs has increased due to the shortage of the supply. Due to the demand from other timber industries such as furniture and medium density board thus, alternative raw material which is not focuses on lignocellulosic material only but also on the residue can be offered. Oil palm stems (Elaeisguineensis Jacq) need to be explored as these stems are abundant after falling from plantations which have not been fully utilized due to their poor properties. The main drawback of oil palm is its low dimensional stability found in the stem parts. Therefore this study investigated the $100 \%$ oil palm stem (OPS) plywood denoted as PTA by optimizing the pre drying process of the veneer by using roller pressing machine, steam dryer and platen press machine. After the OPS veneers have been pre-dried, they were treated with Medium Molecular Weight Phenol Formaldehyde (MMwPF) resin before fabrication of OPS plywood. The product could be promoted as concrete foam, light weight partitions, wall panel and floor slabs. The fracture toughness of OPS plywood developed in this study denoted as PTA was investigated. These properties were compared with the properties of another two types of commercial OPS plywood denoted as PTB and PTC which were manufactured using OPS veneer with tropical hardwood veneer for face and back veneer and control plywood denoted as PTD which was manufactured using $100 \%$ tropical hardwood veneer. The highest value of plain strain and energy release was showed by PTA compared to commercial plywood. The failure was more prominent in wood which showed by the crack propagated line in the veneer layer.

Keywords:

Oil palm stems plywood; medium molecular weight phenol formaldehyde; fracture toughness

Copyright @ 2020 PENERBIT AKADEMIA BARU - All rights reserved

\section{Introduction}

Oil palm which is monocotyledon plant contains vascular bundles and parenchyma tissues. Single fibers in vascular bundles are spongy-like parenchyma tissues and sometimes aggregate by a thin cell walled with hollow structure (metaxylem). Due to this anatomical structure of oil palm, it obtained higher moisture content and consequently swelling and shrinkage more than wood does [1].

The cross-section of OPS is divided into two section namely outer and inner parts. The outer part is about $60 \%$ of the total diameter of the stem and this section is used to produce the veneer. The moisture content is in the range of $200-300 \%$ as compared to the inner section which is $>300 \%$. Previous study by Loh et al.,[2] and Choo et al., [3] reported that moisture content from outer part

\footnotetext{
${ }^{*}$ Corresponding author hasmawi@psa.edu.my
} 
of oil palm stem is lower than inner part. They also in an agreement with Field and Holbrook [4] stated that the lower moisture content found in the outer part was due to the lower amount of pectin hydrogelsas compared to the inner part of OPS.

For plywood production the MC of the veneer is less than $20 \%$ in order to have good stability and bonding performance. Since the MC of OPS veneer is considerably high (200-300\%), the drying process have to be done correctly without damaging the veneer. Historically, the drying of the OPS veneers have been done by;

a) Drying under sun, but take a lot of time and space

b) Oven dry

All the above methods were found not practical due to time consuming and the result are not satisfactory. The drying process of OPS veneer at present are done by oven drying method with all layers of veneer are put together in the oven without segregating the MC of each layers due to time consuming. The typical drying time taken to dry a 5-6 mm thick veneer at about 150 으 $\mathrm{c}$ is between 50-60 minutes and this is considered very long time as compared to the drying time of tropical hardwood veneer which is normally 20 minutes, consequently affected on the increment of processing cost. In order to reduce the variability of the MC of the veneers, this study only used the veneer from the outer diameter only due to the low moisture content compared to the veneer from the inner diameter [3]. Then these selected veneers were undergone the new method of drying process developed in this study. Hence, this study was tried to optimize the drying time by performing pre drying or partially removing the moisture by passing through roller pressing machine prior to oven drying. After oven drying in the oven, in order to be dimensionally stable, the veneer was treated with phenolic resin. Bulking treatment using phenol formaldehyde resin followed by densification is one of the cost effective ways to improve dimensional stability, strength properties and durability of wood against biodeteriorating agent [5]. The phenolic resin managed to swell the intercellular cell wall of lignocellulosic material without bonding to it. The dimensional stability was significantly improved through increment of resin molecular weight [6]. Rabiatol et al., [7] found that the wood treated using low molecular weight phenol formaldehyde (LMwPF) resin can obtain anti swelling efficiency (ASE) values as high as $74 \%$, respectively.

Many study had been carried out in using the phenolic resin to improve the dimensional stability namely Anwar et al., [8] who used low molecular weight phenol formaldehyde (LMwPF) to enhance the properties of laminated bamboo, Kajita and Imamura [9] used this resin to improve the physical and biological properties of particle boards, while Bakar et al., [10] and Nabil et al.,[11] used this resin to enhance the properties of solid oil palm (Elaeisguineensis Jacq) and sesenduk (Endospermum diadenum), respectively.

Hafizah et al., [12] impregnated the veneer with LMwPF and medium molecular weight phenol formaldehyde (MMwPF) found that after the production of plywood, the properties of the LMwPF OPS plywood was not as good as MMwPF treated Oil Palm stem plywood due to the brittleness of the resin.

\section{Methodology}

\subsection{Materials}

\subsubsection{Plywood}

Four sources of plywood were used in this study. PTA is the plywood prepared by the author using $100 \%$ oil palm plywood with the veneers treated with phenol formaldehyde. PTB and PTC were commercial oil palm plywood from two commercial factories. This plywood used tropical veneer for its face and back layer and PTD was tropical plywood. 


\subsubsection{Manufacturing of 100\% Oil Palm Plywood (PTA)}

Three fresh pieces of outer OPS veneers with thickness between 4.5-6.0mm were cut to the dimensions of $4 \times 3$ feet. The veneer was then feed into roller pressing machine with the gap of the roller; $R_{1}: R_{2}: R_{3}=3.5: 2.8: 2.8 \mathrm{~mm}$ and speed of the roller was $8.0 \mathrm{rpm}$ to squeeze out the water. Then, the veneer passing through a continuous roller dryer with temperature at $150^{\circ} \mathrm{C}$ and speed $480 \mathrm{rpm}$ for 1 hour until the final moisture content (MC) of the veneers were $0 \% \mathrm{MC}$. After that, Medium molecular weight phenol formaldehyde (MMwPF) with ratio 80:20 for resin and water respectively and solid content $49.1 \%$ was applied two times on the veneer through glue spreader in gluing process. Then these veneers undergoes plattern press machine for pre-curing process for 9 minutes with the temperature of the plate ranging between $90-140^{\circ} \mathrm{C}$. The targeted $\mathrm{MC}$ at this stage was between $6-20 \% \mathrm{MC}$. These veneers were combined together and subjected to heat and pressure in the hot press until the glue was cured to form plywood panels at a temperature $115^{\circ} \mathrm{C}$ and pressure $120 \mathrm{~kg} / \mathrm{cm}^{3}$ for 15 minutes. After curing the boards are ready to be used. Fig. 1 . shows the different types of plywood used in this study.

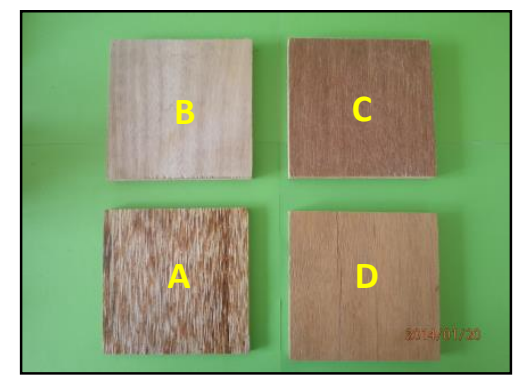

Fig. 1. Different types of plywood; A- PTA, B- PTB, C- PTC, D-PTD

\subsubsection{Methods}

The mechanical properties of the plywood were determined for fracture toughness strength properties.

\subsubsection{Determination of Fracture Toughness Strength}

The fracture toughness test was conducted accordance to American Society for Testing and Materials ASTM D 5045-99 [13] using single edge notched bend test (SENB). A total of 72 specimens were cut from plywood parallel to the beam axis and the fracture set up is shown in Figure 2 . The specimen width, $W$ is two time thickness $B, W=2 B$ and specimens length, $L$, is $L=2.2 W \times 2$. In both geometries the crack length, $a$, should be selected such that $0.45<a / W<0.55$. First a notch of depth that is equivalent to the thickness of the plywood was made using milling machine; a sharp initial crack tip was produced by tapping/sliding a fresh razor blade at the center of the tip of the notch. The initial crack length was prepared between $0.45 \mathrm{~mm}$ and $0.55 \mathrm{~mm}$. These variations in initial crack length are to see the effect of different pre-crack length on the fracture toughness. The pre-crack length (a), was measured using an optical microscope with a 4 times object lens. A three-point load bending test method was applied to all test specimens using Instron 3382 Universal Testing Instrument equipped with a $50 \mathrm{kN}$ load cell. The load was applied with a constant crosshead speed of $5.5 \mathrm{~mm} /$ minutes. The fracture toughness including critical stress intensity (Kic) and critical strain energy release (Gic) was calculated using Equation 1, Equation 2 and Equation 3, respectively. 
$\mathrm{Kic}=6 \mathrm{P} / \mathrm{BW}^{1 / 2}$

where,

$\mathrm{P}=$ Maximum load $(\mathrm{N})$,

B $=$ Thickness of the specimen $(\mathrm{mm})$,

$\mathrm{W}=$ Width of the specimen $(\mathrm{mm})$.

$\mathrm{Y}=1.93(\mathrm{a} / \mathrm{W})^{1 / 2}-3.07(\mathrm{a} / \mathrm{W})^{5 / 2}-25.11(\mathrm{a} / \mathrm{W})^{7 / 2}+25.80(\mathrm{a} / \mathrm{W})^{9 / 2}$

where,

$\mathrm{a} \quad=\quad$ Pre-crack length $(\mathrm{mm})$,

$\mathrm{W}=$ Width of the specimen $(\mathrm{mm})$.

$\mathrm{Gic}=\mathrm{Kic}^{2} / \mathrm{E}$

where,

$E=$ Young's modulus (N)

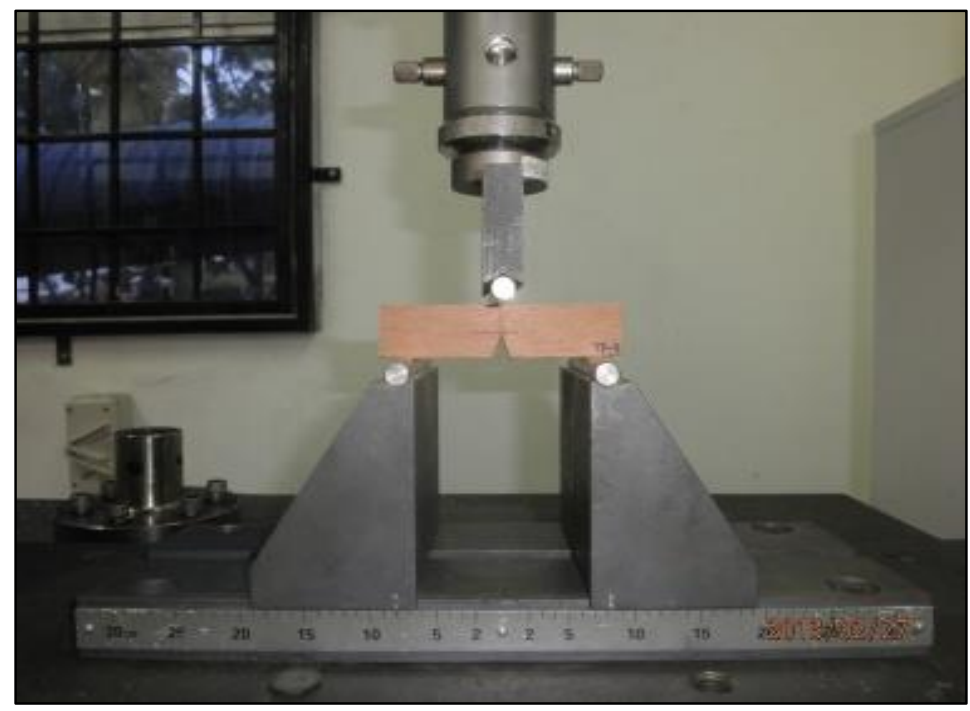

Fig. 2. Experimental Set-up for Fracture Toughness Test

\section{Results}

The mechanical properties of plywood from four different sources were tested and evaluated.

\subsection{Fracture Toughness}

Fracture toughness of the plywood specimen was evaluated by mean of plane strain $\left(\mathrm{K}_{\mathrm{IC}}\right)$ and strain energy release $\left(\mathrm{G}_{\mathrm{I}}\right)$. The plane strain $\left(\mathrm{K}_{\mathrm{I}}\right)$ can be determined by using Equation 1 and Equation 2 while strain energy release $\left(G_{\mid c}\right)$ can be determined by using Equation 3. It was found that fracture toughness had $K_{\mathrm{IC}}$ and $\mathrm{G}_{\mathrm{IC}}$ value range from $10 \mathrm{MNm}^{2}$ and $0.3 \mathrm{kJm}^{-2}$ to $130 \mathrm{MNm}^{2}$ and $58 \mathrm{kJm}^{-2}$, respectively and the highest was PTA plywood as shows in Fig. 3. and Fig. 4. This is possibly due to the highly crosslinked resin which filled the void space of material thus increase the toughness of the material. 
Anwar et al., [14] also found that the medium to low molecular weight phenol formaldehyde resin (2000-600 Mw) is able to penetrate in the lignocellulosic structure. Phenolic resin can improve PTA plywood $\mathrm{K}_{\mathrm{IC}}$ and $\mathrm{G}_{\mathrm{IC}}$ by $225.7 \%$ and $2104.9 \%$ of PTD, $238.6 \%$ and $2297.9 \%$ of PTB and $1187.2 \%$ and $17339.4 \%$ of PTC, respectively. In another study Keledi et al., [15] found that fracture toughness of laminated composite increase with an increment of filler content. They also in an agreement with Pukanszky and Maurer [16] stated that the increment of the fracture toughness was due to the reduction of porosity of the materials.

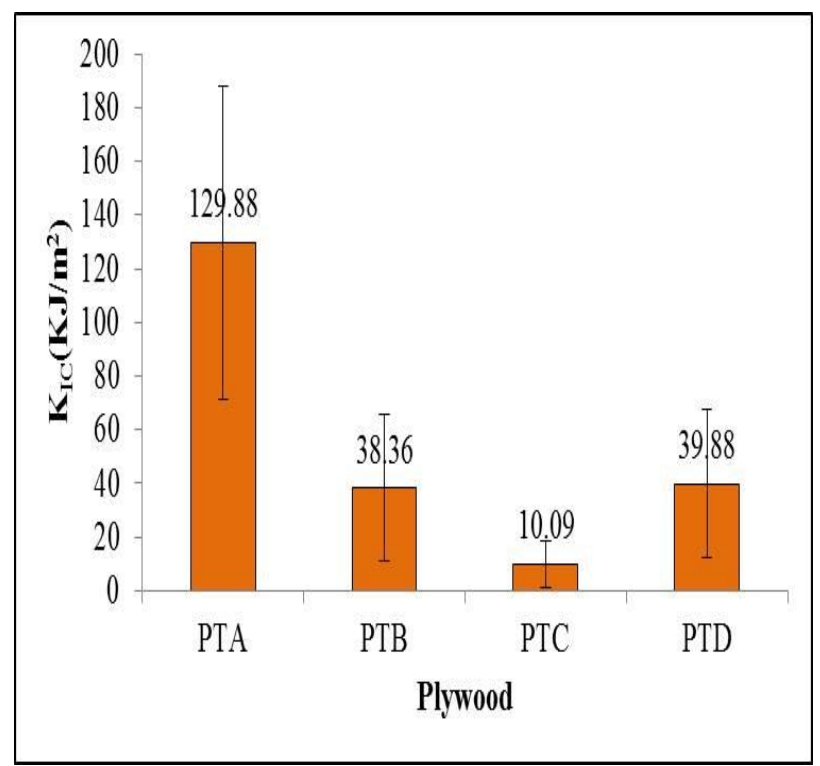

Fig. 3. $K_{1 C}$ of OPS-Plywood (PTA) and Commercial-Plywood (PTB, PTC and PTD)

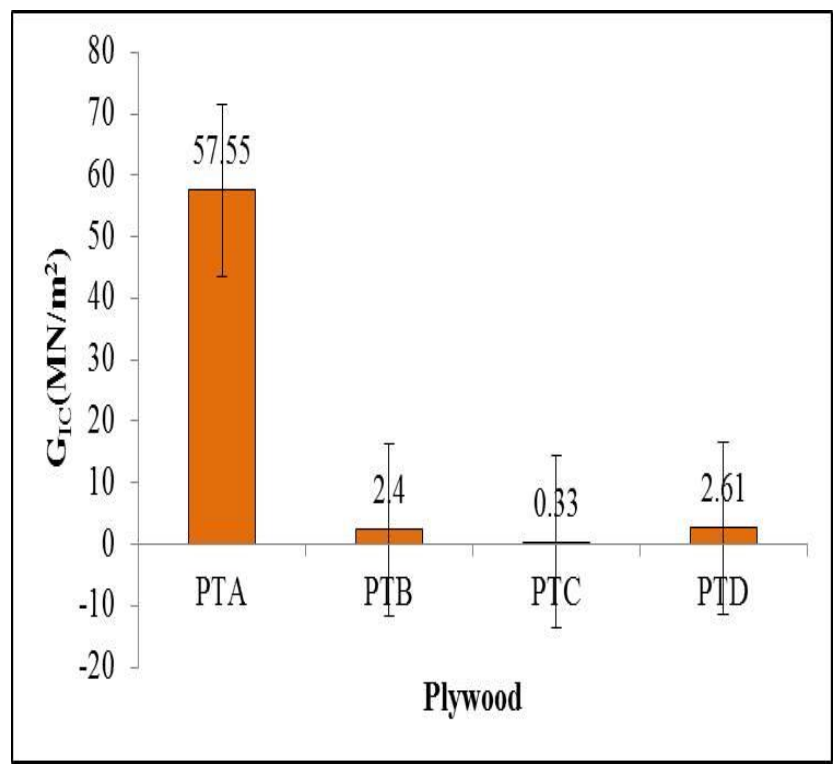

Fig. 4. $G_{l C}$ of OPS-Plywood (PTA) and Commercial-Plywood (PTB, PTC and PTD) 


\subsection{Failure Characteristics of Fracture Toughness}

Fig. 5. shows the mode of failure for OPS-Plywood (PTA) and Commercial-Plywood (PTB, PTC and PTD). It is clearly shows that OPS plywood glued with MMwPF resin (PTA) had unstable crack growth arise from the initial notch as shown in Fig. 5. (a). Under close observation, it is found that the $2^{\text {nd }}$ and $3^{\text {rd }}$ layer of veneer crack following the $1^{\text {st }}$ layer. Fig. 5. (b) however shows more stable pattern of crack growth for PTB. The crack propagates from the initial notch straight throughout the width. The $2^{\text {nd }}, 3^{\text {rd }}, 4^{\text {th }}$ and $5^{\text {th }}$ layer of the veneer was also cracked, however not following the $1^{\text {st }}$ layer of veneer indicating that the failure was on the joint glue. Similar behavior were also observed on PTC and PTD plywood, where it is found that the crack growth straight throughout the width as shown in Fig. 5. (c) and Fig. 5. (d).

This proves that MMwPF resin is able to penetrate in the OPS vascular bundle and parenchymatic cell wall thus improves on the adhesion between polymer and veneer interface. Previous study by Kyziol et al., [17] stated that the filling polymer on the porous wood enhance on the mechanical and fracture toughness of the material.

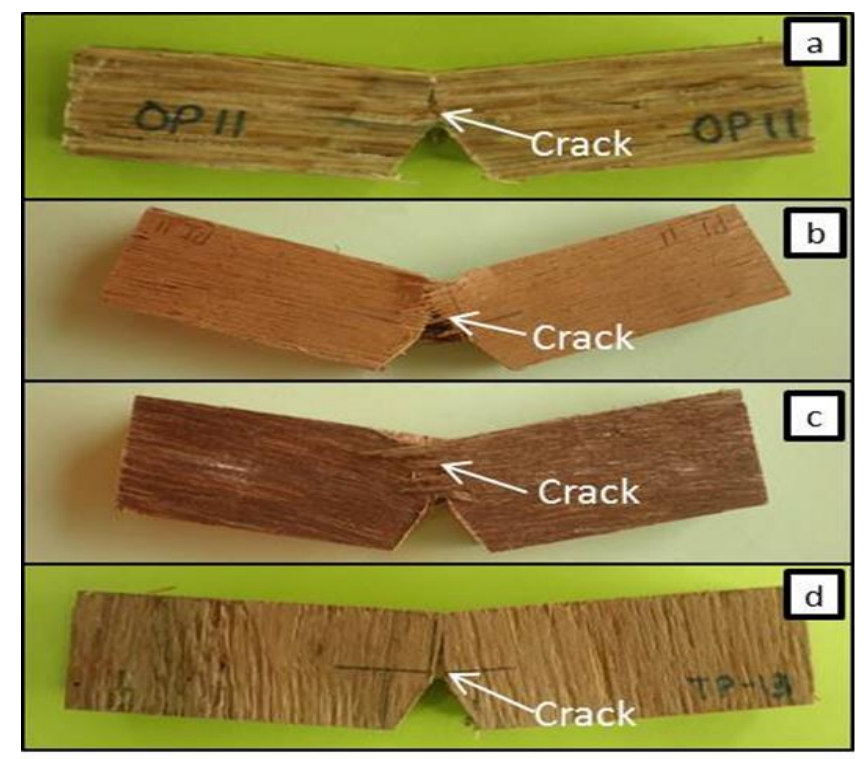

Fig. 5. (a) Failure pattern of PTA, (b) PTB, (c) PTC and (d) PTD

\section{Conclusions}

In fracture toughness, the highest value of plain strain and energy release was showed by PTA compared to commercial plywood. The failure was more prominent in wood which showed by the crack propagated line in the veneer layer.

\section{Acknowledgement}

The authors would like to express greatest appreciation and gratitude to the Universiti Teknologi MARA of Malaysia (UiTM), Universiti Putra of Malaysia (UPM) and Malaysian Timber Industrial Boards (MTIB) for assisting and funding this study. Thanks are also rendered to Plus Intervest Sdn. Bhd and Central Kedah Plywood Industry Sdn. Bhd. for supplying OPS Plywood and processing facalities and Malayan Adhesive and Chemicals (M) Sdn. Bhd. for providing the MMwPF resins. 


\section{References}

[1] Lim, S. C., and K. C. Khoo. "Characteristics of oil palm trunk and its utilization." Malaysian Forester 49, no. 1-2 (1986): 3-22.

[2] Loh, Yueh Feng, M. T. Paridah, Yeoh Beng Hoong, Edi Suhaimi Bakar, Husain Hamdan, and M. Anis. "Properties enhancement of oil palm plywood through veneer pretreatment with low molecular weight phenol-formaldehyde resin." Journal of adhesion science and technology 24, no. 8-10 (2010): 1729-1738. https://doi.org/10.1163/016942410X507795

[3] Choo, Adrian Cheng Yong, Paridah Md Tahir, Alinaghi Karimi, Edi Suhaimi Bakar, Khalina Abdan, Azmi Ibrahim, and Loh Yueh Feng. "Density and humidity gradients in veneers of oil palm stems." European Journal of Wood and Wood Products 69, no. 3 (2011): 501-503.

https://doi.org/10.1007/s00107-010-0483-1

[4] Feild, Taylor S., Maciej A. Zwieniecki, Michael J. Donoghue, and N. Michele Holbrook. "Stomatal plugs of Drimys winteri (Winteraceae) protect leaves from mist but not drought." Proceedings of the National Academy of Sciences 95, no. 24 (1998): 14256-14259. https://doi.org/10.1073/pnas.95.24.14256

[5] Zaidon, A., Edi, S. B., \& Paridah, M. T. (2010). Proceedings from the International Convention of Society of Wood Science and Technology and United Nation Economic Commission for Europe: Compreg Laminates Made From Low Density Tropical Hardwood. ICSWS: Geneva, Switzerland.

[6] Ryu, J. Y., Y. Imamura, M. Takahashi, and H. Kajita. "Effects of molecular weight and some other properties of resins on the biological resistance of phenolic resin treated wood." Journal of the Japan Wood Research Society (Japan) (1993).

[7] Adawiah, MA Rabi'atol, A. Zaidon, FA Nur Izreen, E. S. Bakar, S. Mohd Hamami, and M. T. Paridah. "Addition of urea as formaldehyde scavenger for low molecular weight phenol formaldehyde-treated compreg wood." Journal of Tropical Forest Science (2012): 348-357.

[8] Anwar, U. M. K., M. T. Paridah, H. Hamdan, A. Zaidon, and E. S. Bakar. "Impregnation of bamboo (Gigantochloa scortechinii) strips with low-molecular weight phenol formaldehyde resin." Journal of Bamboo and Rattan 5, no. 3-4 (2006): 159-165.

[9] Kajita, Hiromu, and Yuji Imamura. "Improvement of physical and biological properties of particleboards by impregnation with phenolic resin." Wood Science and Technology 26, no. 1 (1991): 63-70. https://doi.org/10.1007/BF00225692

[10] Bakar, Edi Suhaimi, Mohd Hamami Sahri, and P. S. H'ng. "Anatomical characteristics and utilization of oil palm wood." The formation of wood in tropical forest trees-a challenge from the perspective of functional wood anatomy (2008): 161-178.

[11] Leemon, Nabil Fikri, Zaidon Ashaari, Mohd Khairun Anwar Uyup, Edi Suhaimi Bakar, Paridah Md Tahir, Mohd Anuar Ridzuan Saliman, Mohd Aizat Ghani, and Seng Hua Lee. "Characterisation of phenolic resin and nanoclay admixture and its effect on impreg wood." Wood Science and Technology 49, no. 6 (2015): 1209-1224. https://doi.org/10.1007/s00226-015-0754-4

[12] ASTM. Standard Test Methods for Plane Strain Fracture Toughness and Strain Energy Release Rate of Plastic Materials; (ASTM D5045-99.) American Society of Testing and Materials: Philadelphia, U.S.A., 1999-Reapproved 2007.

[13] Anwar, U. M. K., M. T. Paridah, H. Hamdan, S. Mohd Sapuan, and E. S. Bakar. "Effect of curing time on physical and mechanical properties of phenolic-treated bamboo strips." industrial crops and products 29, no. 1 (2009): 214-219. https://doi.org/10.1016/i.indcrop.2008.05.003

[14] Keledi, G., A. Sudár, Ch Burgstaller, K. Renner, J. Móczó, and B. Pukánszky. "Tensile and impact properties of threecomponent PP/wood/elastomer composites." Express Polym. Lett 6 (2012): 224-236.

https://doi.org/10.3144/expresspolymlett.2012.25

[15] Pukánszky, Béla, and Frans HJ Maurer. "Composition dependence of the fracture toughness of heterogeneous polymer systems." Polymer 36, no. 8 (1995): 1617-1625.

https://doi.org/10.1016/0032-3861(95)99007-H

[16] Kyzioł, Lesław. "Analysis of fracture toughness of modified timber." Polish Maritime Research 17, no. 4 (2010): 5963.

https://doi.org/10.2478/v10012-010-0037-9 